\title{
Bilateral abducens nerve palsy following ruptured anterior communicating artery aneurysm: report of 2 cases
}

\author{
E. Göksu; M. Akyüz; D. Gürkanlar and R. Tuncer
}

Department of Neurosurgery. Akdeniz University School of Medicine. Antalya. Turkey.

\section{Summary}

Isolated abducens nerve palsies associated with intracranial aneurysms have rarely been reported. Their association with anterior communicating artery (ACoA) is even rarer. Intracisternal clot formation and elevated intracranial pressure has been proposed to be the responsible mechanisms.

Herewith, we report two cases of bilateral abducens palsies following ruptured ACoA aneurysms and speculated the possible mechanisms.

Opening of Liliequist's membrane provides clinical improvement due to CSF release.

KEY WORDS: Abducens nerve palsy. Liliequist's membrane. Aneurysm.

Parálisis bilateral del nervio abductor después de la ruptura de un aneurisma de la arteria comunicante anterior. Presentación de dos casos

\section{Resumen}

Rara vez se ha publicado un caso de parálisis aislada del nervio abductor craneal, asociada a un aneurisma. Su asociación con un aneurisma de la arteria comunicante anterior (ACoA) es todavía más rara. Los mecanismos propuestos son la formación de un coágulo intracisternal y la hipertensión intracraneal

Aportamos dos casos de parálisis bilateral del sexto par, después de la ruptura de aneurismas de la ACoA y discutimos los mecanismos posibles.

La apertura de la membrana de Liliequist da lugar a una mejoría clínica , debido a la liberación de l.c.r.

PALABRAS CLAVE: Parálisis nervio abductor. Aneurisma. Menbrana de Liliequist

Recibido: 13-10-06. Aceptado: 2-01-07

\section{Introduction}

Abducens nerve originates from pontomedullary junction. It crosses between anterior inferior cerebellary artery (AICA) and labyrinthine artery and passes through the prepontine cistern, Dorello's canal, cavernous sinus, superior orbital fissure and orbita respectively. Due to its extremely long extracerebral intracranial course the abducens nerve is the most frequently involved cranial nerve in a number of disorders $^{3}$. About $10 \%$ of patients with sixth nerve paresis have bilateral involvement ${ }^{2}$. Isolated abducens nerve palsies associated with intracranial aneurysms have rarely been reported. Their association with anterior communicating artery (ACoA) is even rarer.

\section{Cases}

\section{Case 1}

A-51-year old woman was admitted with sudden onset of headache, vomiting and diplopia. Neurologic examination showed bilateral sixth nerve palsy (Hunt-Hess grade II). Computed tomography (CT) revealed subarachnoid hemorrhage (Fischer grade II) (Figure l A). ACoA aneurysm, determined with digital substraction angiography (DSA) (Figure l B), was clipped succesfully on the sixth day of her admission. Seven days after the operation her left side abducens palsy recovered gradually and one month later she had normal ocular movements.

\section{Case 2}

A-53-year old woman suffering from sudden headache, nausea and temporary disturbance of consciousness was admitted to our clinic. Bilateral abducens nerve palsies were determined on neurologic examination (Hunt-Hess grade II) (Figure $2 \mathrm{~A}, \mathrm{~B}$ ). CT scan showed subarachnoid and intraparanchymal hemorrhage located in basal cisterns, anterior interhemisferic fissure and right frontal lobe (Fischer grade IV) (Figure $3 \mathrm{~A}$ ) and cerebral angiograhy revealed ACoA aneurysm (Figure $3 \mathrm{~B}$ ). Microsurgical clip- 

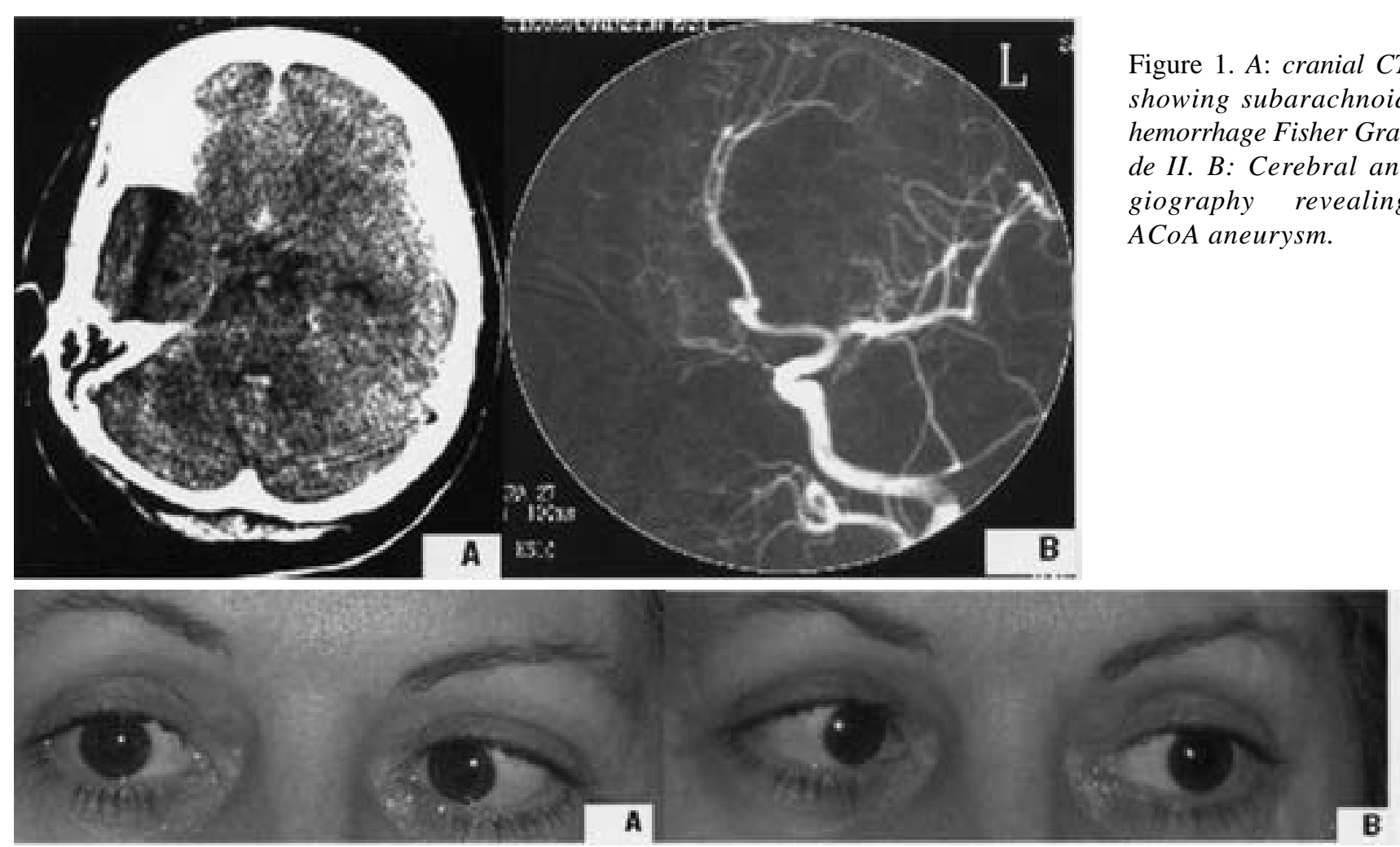

Figure 2. A, B: photograph of the patient showing bilateral abducens nevre palsy.
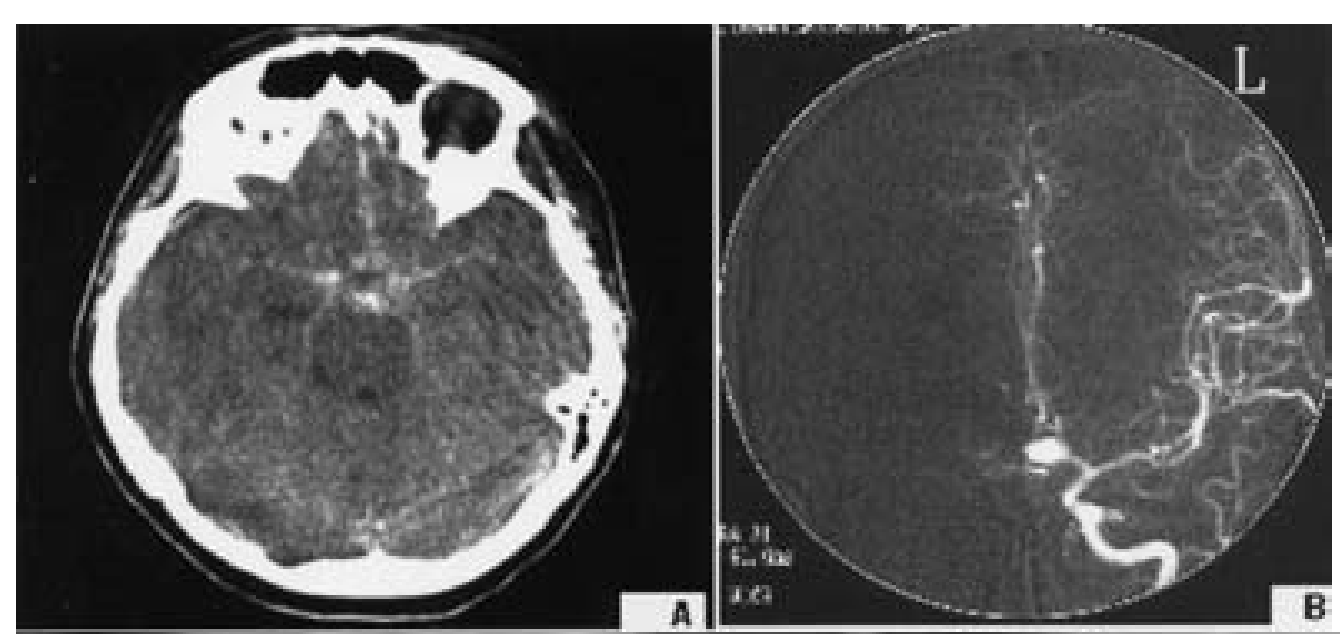

Figure 1. A: cranial CT showing subarachnoid hemorrhage Fisher Grade II. B: Cerebral angiography revealing ACoA aneurysm.

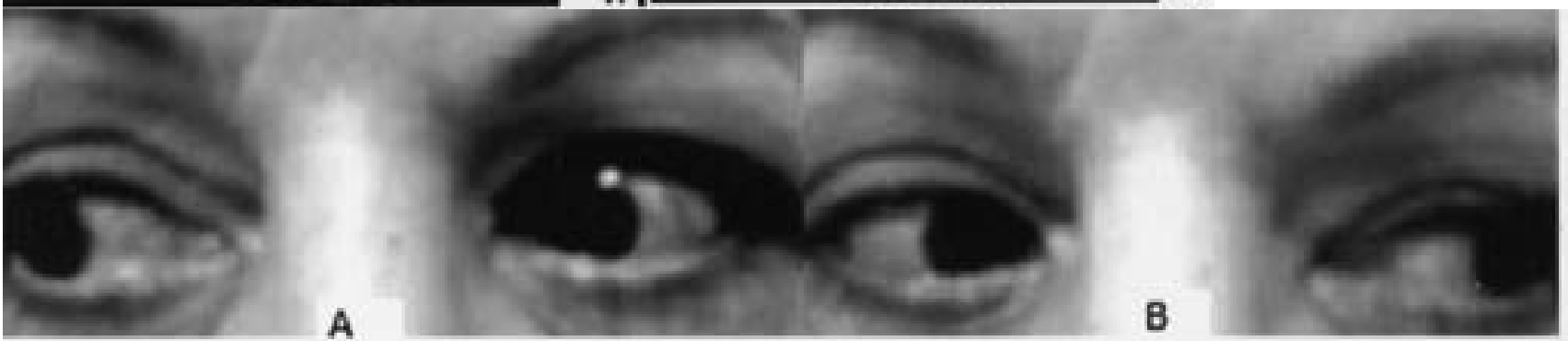

Figure 4. A, B: photograph of patient showing normal lateral ocular movements. 
ping of ACoA aneurysm was performed on the $15^{\text {th }}$ day of her admission. Postoperatively bilateral sixth nerve paresis improved partially and one month later the neuroopthalmologic examination was normal (Figure 4 A, B)

In both cases, Lillequist's membrane and prepontine cistern were opened and meticulous cisternal toilette of the subarachnoid clot was performed during the operation. In the first case high pressure cerebrospinal fluid (CSF) drainage was observed after opening the membrane.

\section{Discussion}

The frequency of abducens nerve palsies associated with intracranial aneurysms is between $3.3 \%$ and $3.6 \%{ }^{1,4}$. Isolated or combined palsies of the sixth nerve had been reported in various aneurysm localisations, including; infraclinoid internal carotid, intracavernous carotid, anterior communicating, basilar, superior cerebellar, vertebral and posterior inferior cerebellar arteries ${ }^{1,4,5,7}$. Several mechanisms have been proposed to explain the bilateral involvement of the abducens nerve after an aneurysm rupture such as: direct compression of the aneurysm, elevated intracranial pressure, vasospasm of the pontine branches of the basilar artery affecting the abducens nuclei and direct compression of the clot on the nerve in the prepontine cistern especially ${ }^{7}$. Because of far way from the anterior communicating artery the mechanism of bilateral sixth nerve involvement following aneurysm rupture has been debated.

The inferior part of the carotid cistern and superior part of the interpedincular cistern are in apposition - sometimes causing a single membrane (Liliequist's membrane, 1959), which may be thick or thin, but normally forming two separate layers.

Following subarachnoid hemorrhage, this arachnoid membrane may become thickened and create a loculation of CSF in the interpedincular and prepontine area. Opening of this membrane at operation almost always results in the escape of some CSF, even in the profuse lumbar drainage ${ }^{6}$.

In the literature two cases of bilateral abducens palsies following ruptured ACoA aneurysm had been reported. In the first case, reported by Nathal et al. (1992) the mechanism of the palsy was explained with the vasospasm of the pontine branches of the basilar artery. and the deficits had resolved completely three months after admission ${ }^{5}$. In the second case, Ziyal et al. (2003) speculated that direct compression of both abducens nerves was caused by the extensive clot in the basal cisterns and bilateral palsies fully recovered on the third postoperative day ${ }^{7}$.

In our first case both abducens nerves were probably affected from the intracisternal entrapment of CSF. In our second case the nerves were affected due to either the intracisternal clot formation as Ziyal et al. speculated or high intracranial pressure caused by the intracerebral hematoma and SAH. In all mechanisms, the direct compression of the nerve is the main cause. We cannot explain the mechanism of the palsy with vasospasm of the pontine branches of the basilar artery because there was neither clinical nor radiological vasospasm.

We believe that the most important physiopathologic mechanism of the bilateral sixth nerve palsies following ACoA aneurysm rupture is the direct compression of the nerve by blood or CSF. Recovery occurs usually 3-8 weeks to literature ${ }^{1,5}$.

\section{Conclusion}

In this report, we speculated that bilateral sixth nerve palsy can occur in the presence of intracisternal CSF entrapment, clot formation and elevated intracranial pressure. Opening of the Liliequist's membrane which provides CSF release and extensive cisternal irrigation of the subarachnoid clot, seems to be an effective surgical maneuver.

\section{References}

1. Berlitt, P.: Isolated and combined pareses of cranial nerves III, IV and VI. A retrospective study of 412 patients. J. Neurol Sci 1991; 103: 10-15.

2. Gaul, C., Pfau, M., Huk, W.J., Heckmann, J.G.: Bilateral paresis of the abducens nerve: report of two cases. European Journal of Neurology 2002; 9: 687-702.

3. Hanson, R.A., Ghosh, S., Gónzalez-Gómez, Levy, M.L., Gilles, F.H.: Abducens length and vulnerability. Neurology 2004; 62: 33-36.

4. Laun, A., Tonn, J.C.: Cranial nerve lesions following subarachnoid hemorrhage and aneurysm of the circle of Willis. Neurosurg Rev 1988; 11: 137-141.

5 Nathal, E., Yasui, N., Suzuki, A., Hadeishi, H.: Ruptured anterior communicating artery aneurysm causing bilateral abducens nerve paralyses-case report. Neurol Med Chir (Tokyo) 1992; 32: 17-20.

6. Yasargil, M.G.: Microneurosurgery, volume 1. Stuttgart, Thieme, 1984; pp 47

7. Ziyal, I.M., Ozcan, O.E., Deniz, E., Bozkurt, G., Ismailoglu, O.: Early improvement of bilateral abducens nerve palsies following surgery of anterior communicating artery aneurysm. Acta Neurochir 2003; 145: 159-161.

Göksu, E.; Akyüz, M.; Gürkanlar, D.; Tuncer, R.: Bilateral abducens nerve palsy following ruptured anterior communicating artery aneurysm: report of 2 cases. Neurocirugía 2007; 18: 420-422.

Corresponding author: Ethem G iksu, M.D. Department of Neurosurgery. Akdeniz University School of Medicine, 07070, Antalya, Turkey 